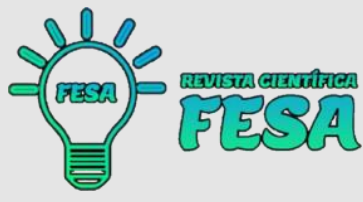

Jul. 2021

v. 1, n. $6,121-136$

ISSN: $2676-0428$

\title{
REVISÃO HISTÓRICA DO CURSO DE PEDAGOGIA NO BRASIL: EDIFICANDO UM CONSTRUCTO
}

\author{
Marinete Pinheiro Regly ${ }^{1}$
}

\section{RESUMO}

O termo Pedagogo, depois da década de 90 e com as novas Diretrizes Curriculares Nacionais do Curso de Pedagogia, faz referência a mais de uma profissão, podendo ser um profissional docente da educação infantil ou séries iniciais do ensino fundamental, ou ainda, o profissional responsável pela coordenação pedagógica ou gestão escolar ou de sistemas de ensino. Dada sua vasta possibilidade de atuação, faz-se prudente detalhar o curso de pedagogia no Brasil, edificando um constructo por meio de uma revisão histórica. Tendo essa meta como ponto de partida, espera-se, com este artigo, dar mais visibilidade para os profissionais que saem dos espaços sistemáticos de formação para as unidades escolares a fim de compreender melhor a sua importância profissional.

Palavras-chave: Pedagogia; Pedagogo; Formação.

\section{RESUMEN}

El término Pedagogo, a partir de los años 90 y con las nuevas Directrices Curriculares Nacionales del Curso de Pedagogía, se refiere a más de una profesión, y puede ser un profesional docente de la educación infantil o de los grados iniciales de la escuela primaria, o incluso el profesional responsable de la coordinación pedagógica o la gestión escolar o los sistemas educativos. Dada su amplia posibilidad de actuar, es prudente detallar el curso de pedagogía en Brasil, construyendo una construcción a través de una revisión histórica. Con este objetivo como punto de partida, se espera, con este artículo, dar más visibilidad a los profesionales que abandonan los espacios sistemáticos de formación para las unidades escolares con el fin de comprender mejor su importancia profesional.

Palabras clave: Pedagogía; Pedagogo; adiestramiento.

\begin{abstract}
The term Pedagogue, after the 90's and with the new National Curriculum Guidelines of the Pedagogy Course, refers to more than one profession, and may be a teaching professional of early childhood education or initial grades of elementary school, or even the professional responsible for pedagogical coordination or school management or education systems. Given its vast possibility of acting, it is prudent to detail the pedagogy course in Brazil, building a construct through a historical review. With this goal as a starting point, it is expected, with this article, to give more visibility to professionals who leave the systematic spaces of training for school units in order to better understand their professional importance.
\end{abstract}

Keywords: Pedagogy; Pedagogue; training.

\footnotetext{
${ }^{1}$ Mestre Em Ciências da Educação pela Universidad USAL

Habilitação em Supervisão e Inspeção Escolar

Pedagoga na EEEFM Bananal

E-mail:marinetepregly@hotmail.com
}

\section{Multifaces do Conhecimento Científico: Teoria e Prática}




\section{INTRODUÇÃO}

Percebe-se, em observação não monitorada em espaços escolares, que os pedagogos precisam ser compreendidos como protagonistas da organização do trabalho pedagógico, agentes articuladores e mediadores, junto aos professores, de metodologias e concepções capazes de promover e desenvolver, como maior qualidade os processos de ensino, aprendizagem e avaliação.

Assim, a reflexão sobre a prática do pedagogo deve sempre partir do porquê ou para quê, pois essa é uma área que se apresenta como uma demanda vital de planejamento, acompanhamento, avaliação e aperfeiçoamento de ações do docente, visando o envolvimento dos professores para que com a riqueza dessa interação, os resultados possam ser alcançados.

Diante de tantos desafios, reconhecemos que nosso estudo poderá ajudar delinear o perfil e delimitar a prática dos profissionais, que atuam diretamente na organização do trabalho pedagógico na escola, quais sejam, os pedagogos. Para tanto, este artigo tem a meta principal de detalhar o curso de pedagogia no Brasil, edificando um constructo por meio de uma revisão histórica. Assim, serão teorizados os seguintes eixos: Pedagogia no Brasil e Perfil profissional do pedagogo; O curso de pedagogia; A pedagogia e seu viés formador

\section{PEDAGOGIA NO BRASIL}

A trajetória de formação do pedagogo é um tema que, embora descrito amplamente em pesquisas que se voltam às discussões da área, será também trazida por nós neste texto. Fazemos isso, porque esta perspectiva histórica sobre a formação nos ajuda a entender os desafios e possibilidades presentes nas práticas desses profissionais nos dias atuais. Essa trajetória traz consigo, elementos significativos e que implicam na constituição do perfil e identidade profissional do pedagogo.

A formação do pedagogo se instituiu legalmente em 1931, por meio do Decreto-lei 19.852, que organiza a Universidade do Rio de Janeiro. O contexto sociopolítico da época era de mudanças para a educação nacional. Naquele momento se instituía a Reforma Francisco Campos, que propiciou a criação do Curso de Pedagogia. De acordo com Dalben (2007):

\section{Multifaces do Conhecimento Científico: Teoria e Prática}


Com a proposta de surgimento de uma instituição superior que se preocupasse com a formação do magistério, seu desenvolvimento e sua especialização, tidos como essenciais para o exercício da docência, notou-se um grande avanço dentro da legislação vigente. Buscava-se uma educação inovadora, influenciada, sobretudo, pela abertura política, na $1^{\underline{a}}$ fase da Era Vargas, 1930 a 1937, e pelos ideais escolanovistas que insurgiam na época. (DALBEN, 2007, p. 6).

Na visão dos Pioneiros da Educação, uma formação em nível superior para os professores poderia contribuir para a realização da crítica e do contraponto com a educação tradicional, que até então imperava.

Teixeira (1958, p. 122) destacou como positiva essa contribuição sob o ponto de vista da crítica ao escrever que tal ação estaria "[...] combatendo a facilidade de tudo admitir [...]". Em 1937 com a instituição do Estado Novo, na segunda fase da Era Vargas, de 1937 a 1945, o então presidente adotou uma política ditatorial e autoritária e que se refletiu em todas as áreas da sociedade brasileira.

Em relação à educação a mudança pode ser percebida pela ênfase dos ideais escolanovistas para imposição de uma universidade padrão para todo o país, advinda do Projeto da Universidade do Brasil (UB), criado em 1937 pelo Ministro da Educação Gustavo Capanema.

Sendo assim, a Faculdade Nacional de Filosofia, Ciências e Letras passa a representar, naquele momento, um padrão para a formação de professores no país (DALBEN, 2007).

Para Cruz (2008), o curso de pedagogia foi criado no Brasil como consequência da preocupação com o preparo de docentes para a escola secundária. Surgiu junto com as licenciaturas, instituídas ao ser organizada a antiga Faculdade Nacional de Filosofia, da Universidade do Brasil, pelo DecretoLei $n^{\circ} 1.190$ de 1939.

Essa faculdade visava à dupla função de formar bacharéis e licenciados para várias áreas, entre elas, a área pedagógica, seguindo a fórmula conhecida como "3+1", em que as disciplinas de natureza pedagógica, cuja duração prevista era de um ano, estavam justapostas às disciplinas de conteúdo, com duração de três anos. Formava-se, então, o bacharel nos primeiros três anos do curso e, posteriormente, após concluído o curso de didática, conferia-se lhe 0 diploma de licenciado no grupo de disciplinas que compunham o curso de bacharelado. 


\section{PERFIL PROFISSIONAL DO PEDAGOGO}

Da origem do curso de Pedagogia comentada acima, ainda surge um agravante, pois surge com um espaço de bacharelado, com duração de três anos, porém o diploma de licenciado seria obtido por meio do curso de Didática com duração de um ano.

Assim, para se obter o diploma de licenciado, o bacharel bastava cursar as disciplinas de Didática Geral e Didática Especial. Vemos, ainda, que o perfil profissional do pedagogo, conforme a regulamentação legal vigente neste período seria o de um profissional técnico da educação, o bacharel, e um professor do curso normal, o licenciado.

Nesse sentido, refletimos que é histórica esta questão da constituição da profissão de pedagogo, ou seja, para ser um licenciado em pedagogia necessariamente não seria preciso cursar um curso de Pedagogia. Isso, em nosso olhar, teve implicações severas na constituição da identidade do pedagogo.

Seguindo o percurso histórico da formação e atuação do pedagogo no Brasil, Dalben (2007) ressalta que anos 40 , aparecem os indícios de atuação do pedagogo na Lei Orgânica do Ensino Primário, Decreto-lei 8529/46, e na Lei Orgânica do Ensino Normal, Decreto-lei 8530/46.

Num período de significativas mudanças com a redemocratização política, Getúlio Vargas adota uma política nacionalista. A Constituição de 1946, de cunho liberal e democrático fez voltar o preceito de que a educação é direito de todos, inspirada nos princípios proclamados pelos Pioneiros da Educação Nova, nos primeiros anos da década de 30.

É neste novo contexto político que a Lei Orgânica do Ensino Primário, considera o pedagogo em suas diversas atuações, a saber: como um técnico em educação, um diretor de estabelecimentos de ensino e um docente de professores.

Conforme a referida Lei Orgânica, o técnico em educação ou gestor escolar alocado nas unidades de organização e direção do sistema escolar de cada Estado, Território e/ou Distrito Federal percebido no artigo 25, tomaria providências quanto a organização e administração do ensino primário, no nível 


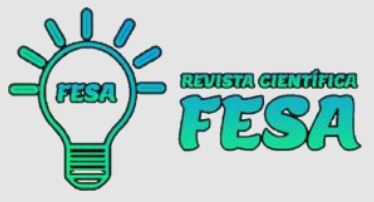

macro escolar, reunindo diversas escolas num único sistema, visando o seu bom funcionamento (DALBEN, 2007).

Este profissional exerceria funções como planejar o ensino, estando sempre atento à comunidade e organizar a estrutura física da escola, tendo em vista seu aparato técnico e tecnológico.

A formação dos professores e do pessoal da administração, também caberia a este profissional, assim como: a organização da carreira do professorado; a organização dos órgãos técnicos centrais para que estes executassem plenamente a direção, orientação e fiscalização das atividades técnicas de ensino e coordenaria as atividades desses órgãos técnicos, junto ao Ministério da Educação e Saúde, para a perfeita articulação dos sistemas regionais e crescente aperfeiçoamento técnico pedagógico.

Outras funções caberiam a este profissional como a de intervir na organização interna da escola e no relacionamento desta com o aluno, considerando o seu ingresso, sua frequência e o andamento de suas atividades escolares.

Podemos claramente perceber nessas atribuições contidas na Lei Orgânica na década de 40, como foi "desenhado" o perfil do pedagogo. Ou seja, o de técnico que, além de elaborar diretrizes, também se constituiu com um "fiscalizador", das ações pedagógicas na escola.

Esse perfil, constituído num período no qual imperava em nossa República outra perspectiva política, pode ser percebido até os dias de hoje. Vemos isso, nas práticas dos próprios profissionais que atuam como pedagogos e, também, nas percepções dos professores e demais profissionais sobre estes pedagogos.

Outro profissional da educação considerado na Lei Orgânica do Ensino Primário é o diretor da escola. A referida lei aponta que sua escolha deveria ser por meio de um concurso entre os professores, sendo critério para sua aceitação neste cargo a experiência na docência e que, ainda, de preferência, tivesse o curso de Administração Escolar oferecido no pós-médio, ou pós-normal, como uma especialização na área educacional.

A mesma lei, em seu artigo 50, apresenta o docente que trabalharia com a capacitação de professores em missões pedagógicas itinerantes para classes de alfabetização, nas zonas populares muito distantes umas das outras. 


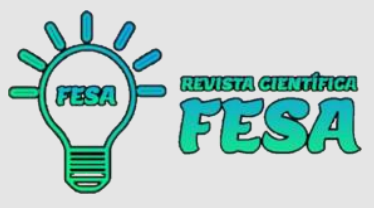

Esse profissional atuaria com a formação e com a orientação dos professores leigos, propiciando-Ihes uma formação em serviço. Destaca-se que esses professores leigos, via de regra, atuavam em escolas muito isoladas e distantes das cidades que beneficiaria muito as escolas isoladas.

A Lei Orgânica do Ensino Normal, Decreto-lei 8530/46, também refletia esta preocupação com a formação de qualidade para os professores primários, principalmente nas zonas rurais do país, que apresentavam um quadro alarmante de mais de $50 \%$ dos professores leigos (DALBEN, 2007).

Nesta lei, estavam contidas, também, orientações voltadas à continuidade da formação de professores especializados, inspetores e diretores nos Institutos de Educação, com o intuito de alcançar qualidade e valorização da educação escolar no Brasil.

Sob esse espírito de reconhecimento e busca de qualificação, é que estão incluídas as referências à formação das diversas atuações do pedagogo como o professor especializado, o administrador escolar e o docente que ministraria no curso normal.

O professor especializado e o administrador escolar são considerados no artigo $3^{\circ}$ do Decreto-lei 8530/46. Este último seria formado em cursos de habilitação, no ensino normal, para serem diretores de escolas, orientadores de ensino, inspetores escolares, auxiliares estatísticos e encarregados de provas e medidas escolares (Art.11).

Aos professores do ensino normal era destinada a formação em cursos "apropriados", em regra, de ensino superior (Art.49). O que abriria precedentes para que egressos de qualquer formação acadêmica pudessem lecionar nos cursos normais.

Podemos dizer que o curso de Administração Escolar pode ser considerado a gênese do Curso de Pedagogia, que teve como pioneiros a Escola de Aperfeiçoamento em 1929 em Minas Gerais e o Instituto Pedagógico em São Paulo em 1938.

Dalben (2007) lembra-nos que a partir destes dois documentos, em linhas gerais, nota-se um avanço na delimitação do perfil profissional do pedagogo e das suas funções que seriam de um técnico da educação que trabalharia tanto em instâncias deliberativas do governo, exercendo funções de inspetor de ensino, quanto na escola, como um diretor responsável pela realidade escolar. 


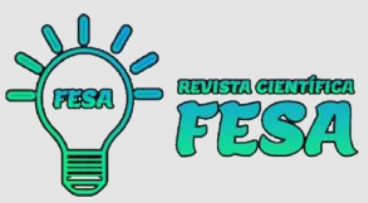

E, também, um docente, atuando no ensino primário e na capacitação de professores primários.

A autora destaca que, nesse contexto, as suas funções envolveriam tanto o interior da realidade escolar, organização e funcionamento da sala de aula e da escola, o acompanhamento de professores e alunos, quanto a inspeção pedagógica das instituições de ensino, a coordenação e realização de cursos de capacitação docente, como as missões pedagógicas itinerantes, e campanhas de educação de adolescentes e adultos promovidas pelos órgãos centrais.

Ainda segundo Dalben (2007), a década de 40 representou uma fase de transição, em que o Curso de Pedagogia ainda não estaria consolidado nos documentos legais, mas delineavam a necessidade de sua formação conveniente, já supondo que esta formação acontecia de maneira incipiente.

Assim, o perfil deste profissional, ainda sem denominar-se pedagogo, tendo em vista que o Decreto-lei 1190/39 estava em processo de tramitação, consideraria as suas diversas atuações como técnico, inspetor, avaliador, diretor, professor e orientador conforme as Leis Orgânicas do Ensino Primário e Normal de 1946.

\section{O CURSO DE PEDAGOGIA}

No início dos anos 60 ocorre uma retomada sobre a formação nos documentos legais, referentes à educação nacional, com o Parecer CFE 251/62, de autoria do relator Valnir Chagas, que fixa o currículo mínimo e a duração do Curso de Pedagogia.

Neste Parecer, percebe-se ainda uma inconsistência do curso. Podemos constatar isso no trecho que segue do referido documento:

\footnotetext{
Não há dúvida, assim, de que o sistema ora em vigor representa o máximo a que nos é lícito aspirar nas atuais circunstâncias: formação do mestre primário em cursos de grau médio e consequentemente, formação superior, ao nível de graduação, dos professores desses cursos e dos profissionais destinados às funções não docentes do setor educacional. Na porção maior do território brasileiro, sem a ocorrência de fatores que no momento estão fora de equação, vários lustros serão ainda necessários para a plena implantação deste sistema. Nas regiões mais desenvolvidas, entretanto, é de supor que ela seja atingida - e comece a ser ultrapassada - talvez até 1970. À medida que tal ocorrer, a preparação do mestre-escola alcançará níveis post secundários, desaparecendo progressivamente os cursos
} 
normais e, com eles a figura do respectivo professor. Ao mesmo tempo, deslocar-se-á para a pós-graduação a formação do pedagogista, num esquema aberto aos bacharéis e licenciados de quaisquer procedências que se voltem para o campo de Educação. O curso de Pedagogia terá então de ser redefinido; e tudo leva a crer que nele se apoiarão os primeiros ensaios de formação superior do professor primário. (PARECER, 251/62, p. 98).

O referido Parecer CFE 251/62 focaliza o pedagogo com base na sua formação para bacharel e licenciado, assim como no Decreto-lei 1190/39, abrangendo um campo e atuação para formação docente e tarefas nãodocentes.

Esse documento, conforme escreve Sousa Neto (1999), foi pouco específico, uma vez que apresentou o Curso de Pedagogia de maneira muito solta, dispersa e pouco conclusiva, deixando a cargo das instituições e do contexto político a definição do perfil profissional para o bacharel e para o licenciado.

Essas características, segundo Dalben (2007), acabam mantendo a indefinição, marcada pela instabilidade e falta de posicionamento para a deliberação quanto aos rumos do Curso de Pedagogia.

Uma situação que, provavelmente, devia-se à aprovação da lei 4024/61, que antecede e orienta tal Parecer, pelo seu longo processo de redação que, segundo tornou esta lei incompatível com a realidade socioeconômica do país. (TAMBINI, 1979)

Percebemos, pelas legislações, que o perfil do profissional da pedagogia ficou então definido de maneira semelhante ao disposto no Decreto-lei 1190/39, pelo Parecer 251/62, dado o tratamento genérico, pouco específico e abordando somente a formação e não a atuação.

O fim dos anos 60, é marcado pela chegada do Regime Militar pelo golpe de 1964. Nesse novo contexto, mudam-se os rumos da educação nacional e também do profissional pedagogo.

Os militares, para legitimar o seu poder na nação brasileira, instituem os atos institucionais, instrumentos que legalizavam suas ações políticas abusivas e a Constituição de 1967, que traduzia a ordem estabelecida pelo Regime, institucionalizando a ditadura. (DALBEN, 2007). 
A educação, em geral, passa a ser influenciada pelo início de uma retomada da expansão econômica e do desenvolvimento industrial, sendo posta a serviço do sistema, incorporando palavras de ordem como eficiência e eficácia, produtividade, racionalização, operacionalização, plena utilização de recursos materiais e humanos. (DALBEN, 2007, p. 09).

A partir de então, os documentos legais relacionados com a educação nacional veem impregnados por uma nova ideologia, marcada pelo tecnicismo, que passa a orientar todos as propostas educacionais, estas focadas no progresso da nação e desenvolvimento do país.

Dentre as legislações do ensino superior, destacamos a Lei 5540/68, da Reforma Universitária Brasileira (RUB), que fixa normas de organização e funcionamento do ensino superior e sua articulação com a escola média. Ela dá um passo significativo para o reconhecimento do pedagogo, ao considerar a obrigatoriedade da formação em nível superior para profissionais que trabalhassem com a formação de professores e no planejamento, supervisão, administração, inspeção e orientação nas escolas.

Na sequência desta lei, é publicado o Parecer CFE 252/69, que trata do mínimo de currículo e de duração para o curso de graduação em pedagogia. Em relação ao Parecer anterior nำ 251/62, percebe-se no atual uma proposta mais elaborada, pois ele faz referência aos documentos legais que influenciaram direta ou indiretamente o Curso de Pedagogia, como o Decreto-lei 1190/39, a Lei Orgânica da sociedade civil da época, já que no início (1948) de sua elaboração incorporou interesses das classes de nível socioeconômico baixo.

Estas novas reformas, pós regime militar, apresentam mais força nas suas deliberações e são mais incisivas, dada à força do regime político ditatorial, pois quando lançavam propostas, estas deveriam ser implementadas de imediato, sem discussões ou possibilidades de debate.

A partir das novas propostas legais percebe-se que o profissional formado no Curso de Pedagogia seria, na sua essência, o professor do ensino normal que poderia exercer, além da docência, as funções de especialistas, ficando a seu critério escolher qual delas seriam.

Toda esta ordenação, segundo Dalben (2007), quanto ao perfil profissional do pedagogo, proposta pelo Parecer CFE 252/69, preparou-o para enfrentar a nova realidade da educação básica que se consolidou com a reforma 


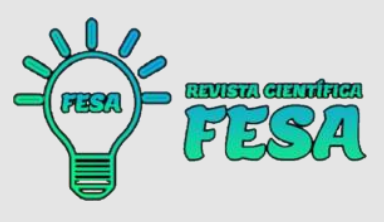

do ensino primário e médio, disposta pela lei 5692/71, que fixa diretrizes e bases para o ensino de $1^{\circ}$ e $2^{\circ}$ graus, e dá outras providências.

Esta lei propôs a atualização e expansão do $1^{\circ}$ e $2^{\circ}$ graus, tendo a escola como uma propagadora da preocupação com a racionalização e a produtividade, assim como estava sendo proposto pela RUB de 1968 às universidades.

$\mathrm{O}$ artigo 33 da referida lei prescreve que a formação de administradores, planejadores, orientadores, inspetores, supervisores e demais especialistas de educação será feita em curso superior de graduação com duração plena ou curta, ou de pós-graduação. (LDB 5672/71)

Dalben (2007) ressalta que apesar da lei as discussões e o reconhecimento do Curso de Pedagogia como fundamental para a formação em nível superior dos especialistas não se consolidam e surgem já em meados dos anos 70 , as indicações 67/75, 68/75, 70/76 e 71/76, elaboradas pela Comissão Especial de Currículos.

Essas indicações se constituíram num desdobramento da Indicação 67/75, Parecer CFE 3.484/75, que trata de estudos superiores de educação habilitações e cursos de graduação, traçando um novo arranjo para os cursos superiores de educação, propondo que a formação do especialista fosse complementar à do professor.

Estes documentos defendiam uma orientação pragmática para a formação dos profissionais da educação, considerando desnecessária a formação dos especialistas em cursos de graduação, visto que sua formação e, consequentemente, sua atuação, era respaldada pela prática, indicando uma nova regulamentação para os estudos superiores de educação, trazendo mudanças estruturais para o Curso de Pedagogia. (DALBEN, 2007)

Muitas foram as discussões empreendidas sobre a formação e atuação do pedagogo até o início da década de 80 e no conjunto desse debate, surge 0 Comitê Nacional Pró-Formação do Educador, em 1980, que pretendeu mobilizar docentes e discentes em torno da reformulação dos Cursos de Pedagogia e de Licenciatura.

De acordo com Dalben (2007), na tentativa de estabelecer alguns parâmetros no debate em todo o Brasil, surge o Parecer CFE 161/86, que trata da reformulação do Curso de Pedagogia, propondo a docência como núcleo básico para a formação de licenciados e pedagogos. 


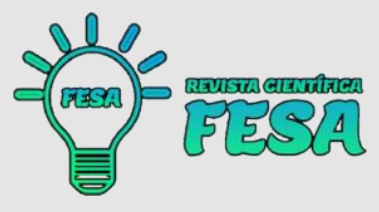

Várias instituições participaram desse processo de reformulação do Curso de Pedagogia, como Instituições de Ensino Superior, Secretarias de Educação, Delegacias do MEC e Associações de Classe, grupos comprometidos com a Educação Nacional que trouxeram uma representatividade considerável para a discussão quanto à formação do pedagogo.

No entanto, conforme escreve Dalben (2007) o Parecer CFE 161/86 não delibera ou define, de maneira clara, quais seriam os caminhos a serem trilhados pelos formadores e formandos do Curso de Pedagogia, apenas mostra a abertura alcançada pelo debate, apresentando o quadro nacional de formação do pedagogo.

\section{A PEDAGOGIA E SEU VIÉS FORMADOR}

O Curso de Pedagogia, inserido neste momento de muitas mudanças, daria ênfase à base docente, oferecendo uma formação generalista. A atuação do pedagogo seria de especialista e docente, este último tanto para o curso normal, quanto para as séries iniciais do ensino fundamental.

Para a autora, esses aspectos em quase nada alteram os posicionamentos dos documentos legais anteriores, já que a docência correspondia à identidade do pedagogo, conforme disposto no Parecer CFE 252/69. E ainda constava como campo de atuação do profissional da pedagogia, desde os anos 40, como disposto nas Leis Orgânicas do Ensino Primário e do Normal, atuando na docência, na orientação, na direção e na inspeção escolar.

Concordamos com Medeiros (2012) quando escreve que somente a partir da década de 1980, já num contexto da redemocratização da sociedade brasileira, é que começa a crítica a essa perspectiva da educação e da formação de docentes, tendo como suporte as teorias críticas da sociedade e da reprodução.

Libâneo e Pimenta (1999, p. 240) apontam que:

A discussão sobre a identidade do curso de Pedagogia, que remonta aos pareceres de Valnir Chagas na condição de membro do antigo Conselho Federal de Educação, é retomada nos encontros do Comitê Nacional Pró- formação do Educador, mais tarde transformada em Associação Nacional pela Formação dos Profissionais da Educação, e é bastante recorrente para pesquisadores da área. Estes já 
apontavam, em meados dos anos $8^{\circ}$, a necessidade de se superar a fragmentação das habilitações no espaço escolar, propondo a superação das habilitações e especializações pela valorização do pedagogo escolar. (LIBÂNEO; PIMENTA, 1999, p. 240).

Medeiros (2012) destaca que, nesse contexto, reaparecem as discussões sobre o curso de Pedagogia, bem como, outros organismos oficiais e entidades independentes de educação, como a Associação Nacional pela Formação dos Profissionais da Educação (ANFOPE), que buscam discutir a identidade do curso. (LIBÂNEO, 2002).

Foram empreendidas muitas lutas e a defesa histórica da ANFOPE se afirmou pela formação superior dos professores da Educação Infantil e anos iniciais do Ensino Fundamental, bem como pela "formação do professor e do especialista no professor", rompendo com a dicotomia entre o bacharel e o licenciado, o técnico e o professor. (MEDEIROS, 2012).

No I Encontro Nacional de Belo Horizonte em 1983 inicia-se a defesa da ANFOPE e fundamenta-se também na necessidade de uma base nacional comum de conhecimento fundamental na formação docente.

Sobre a base comum, dos cursos de formação de educadores, 0 documento orientou que esta deveria abranger três dimensões fundamentais e intrinsecamente relacionadas, a saber (a) dimensão profissional, que requer um corpo de conhecimentos que identifique toda a categoria profissional e, ao mesmo tempo, corresponda às especificidades de cada profissão. Como professores devemos confluir num certo saber e num certo fazer; (b) dimensão política, que aponte para a necessidade de que os profissionais formados pelas diversas licenciaturas sejam capazes de repensar e recriar a relação teoriaprática, o que só pode se dar se tiverem uma formação que permita uma visão globalizante das relações educação-sociedade e do papel do educador comprometido com a superação das desigualdades existentes; e (c) dimensão epistemológica, que remete à natureza dos profissionais da escola, instituição social necessária à transmissão e à elaboração de um saber, onde o científico deve ter um espaço privilegiado.

A base comum deve, portanto, fundamentar-se em uma estrutura científica capaz de romper com o senso comum, sem perder o núcleo do bom senso nele existente (CONARCFE 1988, apud BRZEZINSKI, 1986). 


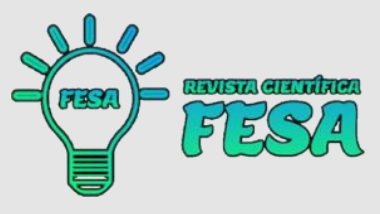

Em relação à nova orientação, Saviani (2008) destaca que as Novas Diretrizes Curriculares Nacionais do Curso de Pedagogia são, ao mesmo tempo, extremamente restritas e demasiadamente extensivas.

De acordo com o autor, as novas Diretrizes da Pedagogia são restritas no que se refere ao essencial, pois se refere àquilo que configura a pedagogia como um campo teórico-prático dotado de um acúmulo de conhecimentos e experiências resultantes de séculos de história.

Ao mesmo tempo são extensivas no acessório, isto é, dilatam-se em múltiplas e reiterativas referências à linguagem hoje em evidência, impregnada de expressões como conhecimento ambiental- ecológico; pluralidade de visões de mundo; interdisciplinaridade, contextualização, democratização; ética e sensibilidade afetiva e estética; exclusões sociais, étnico-raciais, econômicas, culturais, religiosas, políticas; diversidade; diferenças; gêneros; faixas geracionais e escolhas sexuais, como se evidencia nos termos da Resolução antes citados.

Ao longo da história, muito se tem discutido e refletido sobre a prática do pedagogo e, por sua vez, a identidade do pedagogo. Nesse contexto, vemos que nas Diretrizes Curriculares Nacionais estabelecidas em seu artigo $2^{\circ}$, as áreas de atuação do pedagogo incluindo a "docência na Educação Infantil e nos anos iniciais do Ensino Fundamental, nos cursos de Ensino Médio, na modalidade Normal, e em cursos de Educação Profissional na área de serviços e apoio escolar, bem como em outras áreas nas quais sejam previstos conhecimentos pedagógicos" e em seu parágrafo único que "as atividades docentes também compreendem participação na organização e gestão de sistemas e instituições de ensino".

Percebe-se que o debate sobre a atuação do pedagogo é fortalecido, nas novas diretrizes quando se coloca e se posicionas de forma articulada a docência e a gestão no processo de formação e atuação do futuro profissional.

Alguns autores destacam a importância dessa articulação, incluindo a temática da gestão, durante a formação do pedagogo como sendo um importante elemento de apoio para sua atuação. Nesse sentido, encontramos em Ferreira (2009) o argumento de que a gestão constitui o gérmen da formação do pedagogo. 
Percebe-se, de forma explícita, a ampla possibilidade de formação e atuação do profissional da educação, assim como a necessidade de uma sólida formação em gestão da educação, compromissada com os princípios constitucionais, sem o que não teria razão de ser. (FERREIRA, 2009, p. 01).

Libâneo (2006), quando faz a análise da Resolução CNE/CP №. 1/06 inicia pela questão da redução da Pedagogia à docência, considerando a denominação licenciatura no curso de Pedagogia.

O autor pondera sobre a terminologia "participação" do aluno durante sua formação, quanto à questões da gestão e organização da escola e questiona quanto à necessidade do curso prepará-lo para "assumir" funções na gestão e organização da escola.

Franco (2002, p. 5) também contribui com suas análises quando destaca que:

\begin{abstract}
Temos que pensar ainda que a educação se faz em toda sociedade, através de diferentes meios e em diferentes espaços sociais e que, à medida que esta sociedade se tornou tão complexa, há que se expandir a intencionalidade educativa para diversos outros contextos, abrangendo diferentes tipos de formação necessárias ao exercício pleno da cidadania portanto as referências e reflexões sobre as diversas formas e meios de ação educativa na sociedade deverão também constar do rol de atribuições de um pedagogo, e mais que isto, referendar seu papel social transformador. (FRANCO, 2002, p. 5).
\end{abstract}

Concordamos com Medeiros (2012) que a apesar de a Pedagogia ter percorrido um longo caminho, tendo sido discutida, analisada por diversas vezes e por vários autores, a Pedagogia apresenta-se até o momento com uma grande indefinição conceitual. Esta indefinição gera conflitos e tensão, tanto na formação inicial quanto na formação continuada.

Essa constatação surge, pois o pedagogo que atua especialmente no ambiente escolar, mas não somente nele continuam buscando sua identidade profissional e tentando definir um perfil de atuação ante suas múltiplas atribuições.

Acreditamos, assim, que os são os contornos assumidos pela sociedade é que vão delinear os rumos da formação não só do pedagogo, mas de todos os demais profissionais, como se pode conferir em outras áreas de atuação. 


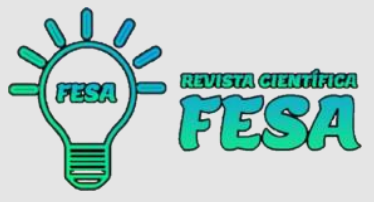

Nesse sentido, outras novas diretrizes poderão surgir em atenção às demandas que tem surgido no interior da escola, no que diz respeito à atuação do pedagogo.

Assim, concordamos com Medeiros (2012) que as mudanças e avanços no processo de formação do pedagogo ainda não correspondem às expectativas dos que almejam ter a identidade do curso definida e capaz de responder em tempo real sua função.

\section{CONSIDERAÇÕES FINAIS}

Entre o desejo e a necessidade, como grandes motivadores, definimos objetivos e traçamos caminhos teóricos e metodológicos que nos permitiram aprofundar no entendimento da temática, buscando elementos que nos permitissem aproximar, principalmente, sob o ponto de vista histórico, da constituição da identidade e da profissionalidade do pedagogo por meio do detalhamento do curso de pedagogia.

Portanto, tais necessidades surgem e, ao mesmo tempo, são compreendidas a partir da afirmação da existência de contextos escolares dinâmicos e nos quais se deve considerar os atravessamentos sociohistóricos, culturais e econômicos que muito contribuem para uma certa instabilidade da identidade profissional do pedagogo.

Em nossa análise e como conclusão, quanto aos aspectos negativos presentes nas novas orientações relacionadas à formação inicial, acreditamos que a falta de consenso para uma proposta de formação do curso de Pedagogia ser ao mesmo tempo uma licenciatura e um bacharelado, acaba influenciando a percepção que se tem de uma formação que, de tão generalista acaba não gerando confiabilidade nas pessoas quanto à formação dos pedagogos.

\section{REFERÊNCIAS BIBLIOGRÁFICAS}

BRZEZINSKI, Iria. Pedagogo: delineando identidade(s). In: Revista UFG / Julho 2011 / Ano XIII no 10. Disponível em: http://www.proec.ufg.br/revista ufg

CRUZ, Giseli Barreto da. Da história do curso de pedagogia e a formação do pedagogo no Brasil. O curso de pedagogia no Brasil na visão de pedagogos 


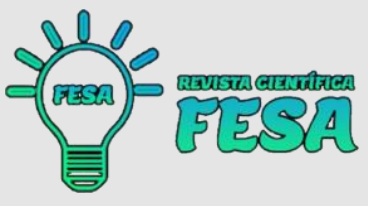

primordiais.2008. 302f. Tese (Dou Janeiro. rio.br/Busca_etds.php?strSecao=resultado\&nrSeq=11787@1>. Acesso em: jan. 2011.

DALBEN, Ângela I. L. de Freitas. O perfil profissional do pedagogo: um resgate na história de construção deste profissional da educação. IV Simpósio Trabalho e educação, ago, 2007. Disponível em: http://www.portal.fae.ufmg.br/simposionete old1/trab comp/tc322.pdf

FERREIRA, Naura Syria Carapeto. Gestão Educacional e Organização do Trabalho Pedagógico. Curitiba: IESDE, 2003.

FRANCO, Maria Amélia Santoro. A pedagogia para além dos confrontos. In: Forum de Educação: pedagogo, que profissional é esse? 2003, Belo Horizonte. Anais...Belo Horizonte: FAE/CBN/UEMG, V. 1 p. 39-68, 2003.

LIBANEO, José Carlos; PIMENTA, Selma Garrido. Formação de profissionais da educação: visão crítica e perspectiva de mudança. In: Educação \& Sociedade, ano XX, № 68, Dezembro/99.

LIBANEO, José Carlos. Pedagogia e pedagogos, para quê? - 8. Ed. - São Paulo: Cortez, 2000.

. Organização da Escola: teoria e prática. Goiânia: Alternativa, 2004

SAVIANI, Demerval. Sentido da pedagogia e o papel do pedagogo. In: Revista ANDE, São Paulo, № 9, 1985.

A pedagogia no Brasil: história e teoria. Campinas, SP: Autores Associados, 2008.

A supervisão educacional em perspectiva histórica: da função à profissão pela mediação da idéia. In: Ferreira, N.S.C. (Org.). Supervisão educacional para uma escola de qualidade. São Paulo: Cortez, 2006. p. 13-38.

TEIXEIRA, Anísio. Por uma escola primária organizada e séria para formação básica do povo brasileiro". Educação e Ciências Sociais, 3(8): p.139-141, Rio de Janeiro, 1958. 